\title{
KŌRLI STALTE LIIVIKEELSEID VAIMULIKKE TÕLKEID: LEER JA MATUSED ${ }^{1}$
}

\author{
RENĀTE BLUMBERGA
}

\begin{abstract}
Annotatsioon. Artikkel on pühendatud liivi kultuuri- ja ühiskonnategelase Kōrli Stalte (1870-1947) 150. sünniaastapäevale. Selles on avaldatud kaks käsikirja, mille Stalte on aastatel 1931-1933 liivi keelde tõlkinud kirikukäsiraamatust ja mis olid mõeldud soome luteri õpetajale Helle Kalervo Erviöle. Erviö oli esimene ja seni ainuke kirikuõpetaja, kes teenis liivlasi nende emakeeles: aastatel 1931-1938 pidas ta mitukümmend liivikeelset jumalateenistust kõigis Kuramaa Liivi ranna luteri kirikutes ning palvetunde liivi taludes, koolides ja surnuaedades, mattis surnuid, ristis lapsi, viis läbi leeriõpetust ja jagas kodudes armulauda. Soome Rahvusarhiivist leitud käsikirjadel ei ole dateeringut ega autorit, seepärast on artiklis kirikukäsiraamatu katkete tõlked dateeritud ja nende tõlkija välja selgitatud. Juttu tuleb ka teistest Stalte vaimulikest tõlgetest, esimestest liivikeelsetest jumalateenistustest ja ristsetest.
\end{abstract}

Võtmesõnad: liivi keel, keele dokumenteerimine, terminoloogia, kirikulugu, läänemeresoome keeled, luteri usk

\section{Sissejuhatus}

2020. aastal möödub 150 aastat tähtsaima liivi kultuuri- ja ühiskonnategelase Kōrli Stalte sünnist (10.08.1870 Irē küla, Läti - 12.01.1947 Fehrbellin, Saksamaa). Ta oli luuletaja, sh liivi hümni sõnade autor, tõlkija (tähtsaim töö uue testamendi tõlge), liivi kuukirja Lìvli toimetaja ja artiklite autor, liivi kirjakeele korraldaja, 1923. aastal loodud esimese liivi ühiskondliku organisatsiooni Liivi Liidu (Līvõd İt) asutaja ja tegevuse korraldaja, esimese liivi koori eestvedaja, Lauri Kettuneni abistaja

${ }^{1}$ Uurimus on valminud Läti riikliku uurimisprogrammi projekti „Läti keel“ alaprojekti „Liivi keel“ (nr VPP-IZM-2018/2-0002) raames. 
liivi-saksa sõnaraamatu koostamisel jm. Selles artiklis käsitletakse ainult seda Stalte tegevusala, mis on seotud vaimulike tekstide tõlkimisega.

Artikli peamine eesmärk on publitseerida kaks avaldamata liivikeelset käsikirja, et täiendada liivi keele korpust, mida Läti Ülikooli liivi instituut praegu arendab ja kus siiamaani ei olnud liturgilisi tekste, ning teha tekstid uurijatele kättesaadavaks. Käsikirjad leidis siinkirjutaja Soome Rahvusarhiivist soome luteri õpetaja Helle Kalervo Erviö² (1906-1951) dokumentide hulgast (Erviö, KA). Tekstid on arhiivi jõudnud 2000. aastate alguses, seega veidi hiljem kui pool sajandit pärast kirikuõpetaja surma. Need on tõlgitud kirikukäsiraamatust: esimene on kirikuõpetaja leeritekst ja kirjutatud Erviö käega, teine aga on loodud matuste tarbeks ja kirjutatud Stalte käega. Kummalegi käsikirjale pole märgitud dateeringut ega autorit. Artiklis soovitaksegi määrata kindlaks nende dateering ja pakkuda tõendeid selle kohta, et tõenäoliselt on mõlema käsikirja liivi keelde tõlkinud Stalte.

\section{Kasutatud allikad}

Dateeringu ja tõlkija tuvastamiseks on kasutatud järgmisi allikaid:

1) kirikuõpetaja Erviö kirjad oma tööandjate tolleaegsele esindajale Matti Pesonenile; asuvad Soome Rahvusarhiivi Pesoneni perekonna arhiivis (Pesonen, KA);

2) Erviö ja Pesoneni kirjutatud artiklid Liivi rannas aset leidnud tegevuse kohta; ilmunud Ärataja Seltsi väljaandes Hengellinen Kuukauslehti;

3) Erviö tütre Riitta Erviö koostatud käsikiri väljakirjutistega ja katkete ümberjutustustega isa kirjadest abikaasale Hilkka Erviöle; koopia asub autori arhiivis (Erviö, RB);

4) keeleteadlase Lauri Kettuneni mälestused sõitudest liivlaste juurde (Kettunen 1948, 1960);

5) autori varasemad uuringud (Blumberga 2006, 2011).

Kahjuks ei ole Erviö abikaasale adresseeritud kirju arhiivile üle antud, välja arvatud üks neist, mis on dateeritud 3. jaanuaril 1938. Tütre koostatud kasinate ümberjutustuste ja väljavõtete järgi võib arvata, et need kirjad

${ }^{2}$ Erviö täitis 1930. aastatel Soome kristliku organisatsiooni Ärataja Seltsi (Herättäjä-Yhdistys) ülesandel mitu korda aastas liivi külades liivi keeles kirikuõpetaja kohustusi. 
annavad kirikuõpetaja tegevusest liivlaste juures põhjalikuma ülevaate kui Erviö kirjad Pesonenile ja Ärataja Seltsi väljaandes publitseeritud artiklid. Tütar on väljakirjutised ja ümberjutustused pannud kronoloogilisse järjekorda, aga ei ole kõigile kirjadele märkinud kuupäevi. Seetõttu ei ole sellele dokumendile viidates alati võimalik esitada täpset kuupäeva.

\section{Liivlaste hingehoid 1930. aastatel}

Liivikeelne liivlaste hingehoid sai alguse alles 1930. aastatel Ärataja Seltsi algatusel. 1930. aasta maikuus külastasid seltsi esindajad Matti Pesonen ja Arvi Malmivaara Lätit ning liivlaste keskset küla Irēt, et selgitada välja liivlaste kristlikud vajadused (Blumberga 2011: 181). Reisi järel leiti, et liivlastel on vaja oma kirikuõpetajat, liivikeelset piiblit või vähemalt uut testamenti ja vaimulikku lauluraamatut (Pesonen 1930: 130), sest need teosed olid kättesaadavad ainult läti keeles. 1930. aasta alguses otsustas Ärataja Selts võtta tööle kirikuõpetaja, kes teeniks ingerlaste koguduses Narvas. Pesoneni algatusel otsustati kirikuõpetaja tööpõldu laiendada ja teha talle kohustuseks kanda hoolt ka liivlaste vaimuelu eest (Pesonen 1999: 325-326).

Ärataja Seltsi palgatud kirikuõpetaja oligi Helle Kalervo Erviö, kes aastatel 1931-1938 pidas kokku mitukümmend liivikeelset jumalateenistust kõigis Liivi ranna luteri kirikutes (Kūolkas, Irēs, Pizās) ning mõne jumalateenistuse Riias ja Ventspilsis (Blumberga 2011: 181-184). Lisaks pidas ta liivikeelseid palvetunde ja jumalateenistusi liivi taludes, koolides ja kalmistuil, saatis ära surnuid, ristis lapsi, viis läbi leeri ning jagas vanuritele kodudes armulauda (sealsamas).

Tõsi küll, esimest korda külastas Erviö Liivi randa juba 1930. aasta augustis, aga siis ei osanud ta veel liivi keelt. Selle reisi ajal elas kirikuõpetaja Stalte juures, tutvus liivi küladega, pidas neis eestikeelseid palvetunde ja õppis liivi keelt (Pesonen, KA: 24.08.1930). Pärast tutvumist kohalike oludega arvas Erviö, et eduka töö jaoks on kõige rohkem vaja vaimulikku lauluraamatut, kirikukäsiraamatu tõlkeid liivi keelde ja uut testamenti (sealsamas).

Uue testamendi tõlkijaks valiti Irē liivlane ja kunagine Irē kiriku köster Kōrli Stalte (köstri kohustusi täitis ta aastatel 1905-1922, vt EKLA), kes oskas väga hästi saksa keelt ja kasutas tõlkimiseks peamiselt Lutheri tõlget, aga ka eesti- ja soomekeelseid tõlkeid ja algset kreekakeelset teksti 
(Kettunen 1960: 164). Tõlge oli valmis juba 1934. aasta alguses (Pesonen, KA: 06.03.1934), aga rahaprobleemide tõttu ilmus uue testamendi mittetäielik väljaanne (evangeeliumid ja Apostlite tegude raamat) alles 1937. aastal ja täielikult 1942. aastal (ŪT 1942). Samasugune saatus oli rahapuuduse tõttu ka liivikeelsete vaimulike laulude raamatul, mille kallal alustas Stalte tööd 1930. aastal (Pesonen, KA: 25.08.1930) ja mille käsikiri oli valmis juba 1932. aasta veebruaris (Pesonen, KA: 13.02.1932). See ilmus aga alles 1939. aastal (LVL 1939), kui liivi külades ei olnud enam ühtegi liivi keelt oskavat kirikuõpetajat.

\section{Käsikirjade dateering ja autor}

Kirikukäsiraamatut ei tõlgitud liivi keelde täies mahus, sest seda läks töökohustuste täitmiseks vaja ainult kirikuõpetajal Erviöl. Seetõttu võib tema kirjade ja teadete põhjal järeldada, et käsiraamatu katked tõlgiti vajadust mööda mitme aasta jooksul. Kui vaimulike laulude kogumiku ja uue testamendi tõlkimise ning väljaandmise kohta pakub asjaosaliste kirjavahetus üsna täpseid andmeid, siis käsiraamatu katkete tõlkimise kohta kahjuks palju teada ei ole.

\subsection{Jumalateenistus ja ristsed - 1931. aasta tõlked}

Arvatavasti algas käsiraamatu katkete tõlkimine 1931. aasta jaanuaris, kui Erviö sõitis teist korda liivlaste juurde. Kuu lõpus 25. jaanuaril toimuski Irē kirikus esimene teadaolev jumalateenistus, mis leidis osaliselt aset liivi keeles: „Pühapäeval ${ }^{3}$ kavatsen pidada jumalateenistuse Pizā kirikus ja siis minna ka teistesse läänepoolsetesse küladesse, samuti pean jumalateenistuse järgmisel pühapäeval ${ }^{4}$ siin koos kirikuõpetaja Häusleriga ${ }^{5}$. Tema jutlustab läti keeles, ma püüan liivi keeles“ (Pesonen, KA: 14.01.1931). Hiljem kirjutas Erviö väljaandes Hengellinen Kuukauslehti, et köster Stalte oli liivi keelde tõlkinud liturgiakatked, seetõttu leidis ka altariteenistus osaliselt aset kahes keeles, läti ja liivi

3 18.01.1931.

${ }_{4} 25.01 .1931$.

${ }^{5}$ Kirikuõpetaja Arnold Häusler oli Riia eesti koguduse õpetaja, kes oskas eesti ja läti keelt ning kes sõitis korra kuus Irēsse jumalateenistust pidama, sest kogudusel ei olnud tollel ajal oma õpetajat. 
keeles (Erviö 1931a: 31). „Esimene täielikult liivikeelne jumalateenistus altariteenistuse ja lauludega" toimus aga poole aasta pärast, 9. augustil 1931 Irē kirikus (Erviö, RB: 08.1931): ,Senini ei pidanud ma jumalateenistusi täies mahus, aga nüüdseks on õnnestunud tõlkida liivi keelde terve kirikukäsiraamatu osa, mis jumalateenistuse kohta käib. Kui sellele vastav jumalateenistus Irē kirikus peeti, oli kohale tulnud suur hulk liivlasi“" (Erviö 1931b: 160). Niisiis oli selleks ajaks käsiraamatust juba tõlgitud jumalateenistuse pidamiseks vajalik kirikuõpetaja tekst. Ka see tekst leiti Erviö dokumentide hulgast Soome Rahvusarhiivist ja on avaldamiseks ette valmistatud.

On teada, et esimesed liivikeelsed ristsed viis Erviö läbi samuti 1931. aastal, kui ristiti neli last (Erviö 1932: 82). Usutavasti ristiti esimesed kaks last augustis: 7. kuupäeval Sīkrõgis ja järgmisel päeval Vaidis, kus ristiti Berta Bertholdi kaheaastane vend (Erviö, RB: 08.1931). Berta Elizabet Berthold (abielus Mangule, 1915-2001) oli Ärataja Seltsi kasvandik ja omandas seltsi toel halastajaõe kutse Soomes (Blumberga 2011: 173). Nendest ristsetest on oma mälestustes põhjalikumalt kirjutanud Lauri Kettunen (1960: 159-161), kes oli palutud lapse ristiisaks. Tõsi küll, mälestustes nimetab ta oma ristilapseks Kōrli (Kōrli Berthold, sündinud 1926), kuigi vanuse järgi oli selle au jaoks sobivam tema kolm aastat noorem vend Bernhard Berthold (1929-1941). Kahjuks ei olnud käsiraamatu katket ristsete tekstiga Erviö dokumentide hulgas arhiivis. Samuti ei ole seda õnnestunud leida ka teistest arhiividest. Võimalik, et liivikeelne ristsete tekst ei ole säilinud.

\subsection{Leer - 1932. aasta suvi}

1932. aasta kevadel otsustas Erviö laiendada oma tööpõldu leeriõpetuse ja pühapäevakooliga: „Kui hästi läheb, tahaksin ma suvel viia läbi leeriõpetuse liivi keeles, sest siis on õpilased kodus. Proovin korraldada ka pühapäevakooli tööd. Kõigis külades ei ole liivi keelt oskavaid lapsi ja teistes külades tegutseb jälle baptistide pühapäevakool, aga võib-olla võiks mõnes külas sellise läbi viia“"(Pesonen, KA: 04.03.1932). Tundub, et mõte pühapäevakoolist jäigi mõtteks, aga esimene liivikeelne leer leidis aset 23. juulil 1932 (Erviö, RB: 22.07.1932). Veel 8. juulil kirjutas kirikuõpetaja oma abikaasale, et ta tahaks teha leeriõpetuse, aga ei olevat ühtegi noort, kes seda sooviks (Erviö, RB: 08.07.1932). Paari nädala pärast 
oli tal aga juba kaks õpetatavat: „Lepste ${ }^{6}$ tütrele $^{7}$ viin läbi leeriõpetust, teisi pole. Järgmisel nädalal Vālgama $\bar{a}^{8}$ pojale, leeritan kodus, mõlemad liivi keeles“ (Erviö, RB: 15.07.1932). Praegu ei ole teada, kelle kolmest Lepste kasutütrest ja neljast Volganski pojast õpetaja Erviö täpselt tollel suvel leeritas. Vanemate nimede järgi võib järeldada, et tegu oli aktiivsete liivi perekondade lastega.

Esimesi liivikeelseid leeriõpetusi kirjeldas õpetaja Erviö kirjas oma tööandjale niimoodi: „Minu viimasel sõidul Liivi randa said esimesed liivi noored omakeelse leeriõpetuse. Kasvandikke oli kaks, kellest üks leeritati Irē kirikus 24. juulil ja teine eelmisel päeval oma kodus, sest ta oli haige ega saanud kirikusse tulla. Vähemasti sai leerijumalateenistusest ilusasti kaunistatud kirikus meeldejääv sündmus. Jumalateenistusel esines noorte liivlaste koor, kes laulis jumala austamiseks vaimulikke laule"(Pesonen, KA: 05.08.1932). Eelnevast võib järeldada, et leeriks vajaminev käsiraamatu tekst oli tõlgitud hiljemalt 1932. aasta juuli teises pooles.

\subsection{Matused - 1933. aasta või siiski 1931. aasta suvi}

Esimeste matuste ja vastavalt ka kirikukäsiraamatu asjakohase fragmendi tõlke dateeringu ümber on rohkem segadust. Varem arvati, et esimesed liivikeelsed matused peeti 1931. aasta augustis (Blumberga 2011: 182). Selline seisukoht tulenes Kettuneni 5. augustil 1931. aastal dateeritud kirjast, milles Kettunen kirjeldab soome ökonomistile ja liivlaste toetajale Yrjö Jahnssonile liivi ühiskonnaelu uudiseid ja kirjutab muu hulgas, et õpetaja Erviö on juba ,liivi keeles ristinud lapsi, jaganud armulauda ja lugenud surnute eest hauarahu palveid [siunannut vainajia haudan lepoon]" (Jahnsson, KA: 05.08.1931). Ometi ei ole teistes praegu autori käsutuses olevates dokumentides ega kirikuõpetaja enda kirjades ja teadetes andmeid ei 1931. aastal ega 1932. aastal peetud matuste kohta. Alles 1933. aastal kirjutab Erviö teates oma Liivimaa töö kohta, et sellel aastal on olnud ka üks matus (Erviö 1934: 108). Seetõttu on vägagi võimalik, et esimesed liivikeelsed matused peeti alles 1933. aastal. Muidugi ei välista see, et matuste jaoks vajaminev käsiraamatu katke oli tõlgitud juba 1931. aasta suvel, sest siis leidis aset aktiivsem käsiraamatu tõlketöö ja Kettunenil

\footnotetext{
${ }^{6}$ Maṛt Lepste (1881-1958), liivi keele õpetaja ja Liivi Liidu juhataja.

7 Tegelikult oli ta Lepste kasutütar.

8 Didrõk Volganski (1884-1968), liivi ühiskonnategelane ja Liivi Liidu juhataja.
} 
pidi olema põhjust kirjutada matuste kohta, mis olid just kui liivi keeles aset leidnud (tõlgitud tekst ja mõne sobiva surija ootamine?).

\subsection{Kōrli Stalte - katkete tõlkija}

Miks võib kirikukäsiraamatu mõlema fragmendi tõlkijaks pidada Kōrli Staltet, kui ainult matuste kulg on kirjutatud tema käega? Mis tõendab tõlkija autorsust? Kas või see, et Erviö ise ei maini kuskil oma tööst liivlaste juures rääkides, et ta oleks tõlkinud fragmente käsiraamatust. Tänu käsiraamatu tõlkimise eest avaldab ta ainult professor Kettunenile ja köster Staltele. Sealjuures Kettunenile ainult 1931. aastal: „[..] ja sellel nädalal on kavas esimesed liivikeelsed ristsed. Professor Kettunen ja härra Stalte on tõlkinud katked käsiraamatust, nii et väikeste sammudega läheb töö siin edasi“ (Pesonen, KA: 03.08.1931); „Oleme koos prof Kettuneni ja hr Staltega tõlkinud käsiraamatut. Tõsi küll, minu osa on selles töös olnud väga väike“ (Erviö, RB: 07.08.1931); „Samuti pole võimalik jätta mainimata seda abi, mida professor Kettunen on pakkunud just käsiraamatu katkete tõlkimisel“" (Erviö 1932: 83).

1931. aasta suvel tegeles Lauri Kettunen koos oma tudengite Aulis Rissaneni, Urho Tuomola ja Väinö Kyröläga Irēs Stalte juures oma liivi keele sõnaraamatu käsikirjaga (Kettunen 1960: 153-154) ning võis seega aidata ka Erviöl, kes tollel suvel töötas liivi külades juuli lõpust kuni augusti keskpaigani, nii liivi keelt õppida (Erviö, RB: 08.1931; 12.08.1931) kui ka kirikliku käsiraamatu tekste tõlkida. Kahjuks ei kirjuta Kettunen oma mälestuses midagi selle kohta, milline oli tema enda panus sellesse töösse. Arvatavasti aitas Kettunen siiski pigem luua uusi ja valida välja sobivaid sõnu jms, mitte ei tegutsenud peamise tõlkijana. Seda versiooni toetab ka see, et hilisematel aastatel nimetab Erviö kirikukäsiraamatu fragmentide tõlkijana ainult Staltet: ,Neist abilistest toome eriti esile köster Stalte, vaimulike laulude ja piibli katkete ning käsiraamatu fragmentide tõlkija [...“" (Erviö 1933: 109); „Köster K. Stalte on endiselt tõlkinud katkeid kirikukäsiraamatust [...“" (Erviö 1934: 109). 


\subsection{Tekstide kirjaviis}

1930ndad, mil ka vaatlusaluse käsiraamatu tekstid on tõlgitud, olid liivi kirjakeele ${ }^{9}$ aktiivse arendamise aastad: ilmusid kuukiri Līvli (1931-1939), Liivi sõprade seltsi Lätis kalendrid (1932 ja 1933), Pētõr Dambergi koostatud lugemisraamat koolidele ja kodudele ,Jemakīel lugdõbrāntõz skūol ja kuod pierast"“(1935) ja teised. See oli aeg, millal Valts Ernštreitsi arvates algas liivi keele uus arengujärk, mis kestis kuni 1960ndate lõpuni: „Teine 20. sajandi arengujärk algab väga selgelt ajakirja Līvli ilmumisega aastal 1931, mil kirjakeeles võetakse süsteemsele kasutusele rida uuendusi, sealhulgas juba 1920. aastatel väljapakutatud põhimõtted [..]“" (Ernštreits 2010: 183). Ka käsiraamatu tekstide tõlkija Stalte osales aktiivselt selle perioodi liivi kirjakeele arendamisel ning just selle tõttu on liivikeelsetes tekstides kasutatud selle ajastu ortograafiat ja keelevorme.

Mõlemad käsikirjad avaldatakse alljärgnevalt algupärases ortograafias, st need ei ole ümber pandud tänapäeva liivi keele kirjaviisi. Publikatsiooni on alles jäetud ka kõik ümberkirjutamisel tekkinud vead.

\section{Lõigud kirikukäsiraamatust}

\subsection{Leer}

Selles tekstis on ka mõned soomekeelsed sõnad. Et eraldada neid liivikeelsest tekstist, on need pandud nurksulgudesse.

1. Introitus: Sā virgõ, sā virgõ, Tsion! Ēdi entšta entš joudõ ja entš knašǐš āriniš. Sin nuord sodamied àt syndõn kui kastug uomõg valst. - Nei rõkandõb Izand: Ma tāb sīnda entšõn kīldõ iganis ja entšta andõ kīlõks õigõms ja kuods ja alastõms ja usks ja sād tundõm Izandt. - Ouv volgõ Izan ja Puogan ja Pivan Vaimõn!

2. [Puhe]

3. Nei rõkandõb Izand: Kis ỵ̣ min tapartõb rou jeds, yḷ sie ma ka tāb tapartõ entš Iza jeds, kis um touvõs.

Sie mäd Izand Jēzus Kristus sõna pāl ma kizub sin kädst:

${ }^{9}$ Liivi kirjakeel on kujunenud 19. sajandi keskpaigast alates ja selles protsessis on olnud mõned etapid, mida oma doktoritöös on põhjalikult uurinud ja täpsustanud keeleteadlane Valts Ernštreits (2010). 
1. Kas sa 1̄š entšõst tapartõd sieldõ ja julgiz tundõmiz pierrõ, ku sa kuolmainagiz Jumal, Iza, Puoga ja Pyva Vaim pāl uskud, nei ku ta entšta entš sõnas um nägtõn ja nei kui mäd evangelium-luter usk lātkub sieda uskõ täm pyva sõna pierrõ sieldõ ja pūdist tapartõb ja tieutõb, siz kīt: Ja.

2. Tapart 1̄š sydamõks ja sūkõks Jumal ja lātkub jeds sieda entš uskõ, mis pāl sa uod rištõt ja missäš sa uod opatõt.

3. Kas sa tād sie usk jūr ja leb sie ka evangelium-luter usk lātkub tapartõks jūr iedõ, ku mēg patlist leb alastõm - set leb usk Jēzus Kristus pä̉ - pivalisõks sām ja kas sa tād ka jellõs ja kuolõs sie jūs vizastis piddõ, siz kīt: Ja.

4. Kas sa tõitad sydamõst sieda tādõl pānda, sie usk pierrõ jellõ, entš Pästajizõn alantõms kūldzi tagan kädõ, Jumalt ārmastõ amast sydamst ja entš ležglist nei īš kui entšta, siz kīt: Ja.

5. Kas sa ka tõitad, laz sa nei võigõ jellõ ja kädõ, äbväzzõs tarpõl pānda pallõs Izand alastõm andõ, sõnnõ ja zakramentõ, siz kīt: Ja.

4. Izand um sieda kūlõn! - Ja seḷli sin tapartõmiz ja tõitamiz päl võtab ma entš amat puolst, kui evangelium-luter usk pyvakuoda kutstõt ja pandõt pālkali täm nims sīnda täm tävd õigiz itlizõks vastõ, laz sinnõn nei kui siedaigsāņi Jumal sõna jūs volgõ jagu pyva õdõgiz ja amad mūd alastõmandõd, pyvastõmõd ja õigõmt jūs, mis Izand entš lātkubbõn mā pāl um andõn, ja ma tapartõb, ku sa usks pīlõd lopandõks sāṇi, sinnõn ka līb ykškõrd jaggõ äbkaddijiz pierandõks ja äbulzkītõb iganiz jelamiz riem jūs. Amen.

5. Tul ny ja võta usklis sydamõs vastõ Izand pyvastõmt: Arm Jumal pyvastõg sīnda leb ja leb, ja ama, mis sinnõn um, vaim ja jeng ja leja, sāgõ voitõt äbriktõt mäd Izand Jēzus Kristus tulmiz pāl! Amen.

Nei rokandõb Izand: Vol ustõb kuolõm sāṇi, siz ma āndab sinnõn jelamiz vāņka. Siepierast vol viza, äbliktõb ja sā īdõ kaval ju tädõks Izand ties. Siepierast ku Jumal um ustõb, kis sīnda um kutsõn. Mäd Izand Jēzus Kristus aru volgõ ja iegõ sinkõks! Amen.

6. [Puhe seurakunnalle.]

7. [Rukous.]

Nei rokandõb Izand: Tulgid amad min jūr, kis tēg uot vājastõt ja kāndam allõ ja mā tāb tēḍi virtõ. 
Vondsõst āt ne, kien um siemiz ja juomiz nālga õigõm tagan, siepierast ku näntõn um täutõdõn sāmist.

\subsection{Matus}

Matami.

1. Iza, Puōga ja Pyva Vaim nims. Amen!

2. Rõk.

3. Panmõ tädõl Jumal sõnnõ ja kūldõgid mis ta tapartõb yḷ rišting kaddõjiz kazam: Rišting, naizõst syndõn, jelab lītiz yrg ja um täuž äbarmõ, ta kazab kui pusk ja pudub jara, ūrgub jedst jara kui vāṛ ja äb iē paikõl. Põrmõn um sāmõst tegiž mā sizzõl, kui ta um vond ja vaimõn tegiž Jumal jūr, kis um andõn tända.

(Kazzõn jūs.) Mēg uōm Sin jeds vỗrõd ja kylalist, kui amad mäd izad. Kūldõgid kui Jumal sõna mädlõb mäddõn vaḷmõdõn vōlda kuōlõm pierast:

Pan kõrdõl entš kuota, siēpierast ku sinnõn um kuōlõmõst. Ymmar nimud volgõ täddõn kāḷ sidtõt ja täd kȳṇdõld palagõd; volgid virgs, siēpierast ku tēg äd tiedat, kuna kuod izand tulab, kas ta tulab õdõn, või puōlstyedõ, või kikiš, või uōndžõl, algõ ta tulds tẩ,̣i liēdag magõmõs. Algid jeksõgid mittõ, Jumal äb las ēntšta kēḷštam: mis rišting kȳlab, sieda ta nītõb.

Võtagid sydam jūr, kui leja kaddõjis kazams Jumal sõna mäḍi riēmtõb:

Kuōlõm um patud pālka, aga igani jelami um Jumal and löb mäd Izand Jezus Kristus. - Kristus um ylznūzõmi ja jelami; kis täm pāll uskub, jelab, ku ta ka kuōlõb ja kis jelab ja uskub täm päl, se äb kuōl iganõs. Stuṇd tulab, kiēns amad, kis ōdiš (kālmiš) āt, täm yeldõ kūlõbõd ja tulbõd ulzõ, kis jõvvõ āt tiēnd, jelamiz ylznūzõmiz pāll. - Kuōlõm um jara niēldõt võitõ. Kuōlõm, kus um sin ả̉nda?! El, kus um sin võit?! Aga tienandõks volgõ Jumalõn, kis mäddõn võitõ um andõn löb mäd Izand Jezus Kristus. Amen!

(Laps jūs.) Kūldõgid ka entš riēmtõmiz pierast, mis Izand, kuoḍin yl lapst kītõb, siēpierast ku nei um kēratõt: Siēs entšs stun,ds oppõjist astist Jezus jur ja rõkandist: Kis um se ama sūr touvõ valds? Jezus kutsiz ȳd laps entš jūr ja pan, siē sydamõl nänt vail 
ja rõkandiz: Tuodlist, ma kītõb täddõn, až tēg ymmar äd kiērõt ja äd sāt sellıistõks kui lapst, siz tēg äd sāt touvõ valdõ.

Pangõd tẩdõl, ku tēg mitȳtõ nāšti piškist äd puolgõt; siēpierast ma kītõb täddõn ku nänt engõld näbõd min Iza palgõ touvõs ȳdõkabal.

4. Āndam ni entš kuōlõn veḷ (sõzar - siē kuōlõn laps) leja ōdan (kālman) kui siēmt ylznūzõmiz pāva pierast:

Māstõ sa uōd võttõt, māõks sinnõn um sāmõst, māstõ Izand Jezus Kristus virgtõb sīnda peris pävan.

5. Pālam Jumalt:

(Kazzõn jūs) Alastli, igani Jumal! Sa uōd löb entš ainagisyndõn Puōga Jezus Kristus kuōlõm ja ylznūzõmiz, kuōlõmõn võimist võttõn, nei ku ta mäddõn, až mēg uskõm, äb või emin kajjõ tiēdõ.

Kiēr entš iza pālga mäd, entš lapst, puōl ja laz se ōda (kālma) mädlõg mäddõn, mäd kazzõks, ku ka mäddõn um laggõmõst siēst māilmast, kuna sa sieda tād ja mäḍi kutsud. - Opat mäddõn tuožist tâdõl pānda: ku kuōlõm um patud pālka, aga ku igani jelami um Jumal and, tund löb mäd Izand Jezus Kristus, ku mēg entš iga yrgõ, mis sa mäddõn täsa pästamizõks āndad, jõvist ažžõl panm, entš mitmõsugliži patidi jara tundõm, sydamõst ēntšta sin puōl kiērõm, sieda votšõm, mis yllõ um, kus Kristus mäd Pästaji jelab, jega pā̄va pattõn kuōlõm ja õīgõms ja pyvams sinnõn palkõm. Riemtõji Jumal, täut näntõn sydamd entš Pyva Vaimõks, kis muraglist àt yḷ siē maggõm innõn jeng laggõmiz; laz ne võtagõd joudõ ja sāgõd virtõt jelamiz sõnast ja ānda näntõn ja mäddõn amadõn entš alastõmt, laz mēg siz, ku mäd stuṇd tulab, võigõm arms tästa laggõ ja ykškõrd pyvalist ylznūzõ löb sin ārmaz Puōga, mäd Izand ja Pästajiz, Jezus Kristus, kiēn nims mēg pālam:

(Laps jūs.) Ama vägi, alastli Jumal ja Iza, kis Sa uōd kutsõn siē ārmaz laps jeng māilma jelamizõst pyvastõtõ touvõ riēm vodlõmizõ, mēg alantõm ēntšta Sin ama vägiz käd ala ja pālam Sinda: ānda muraglist vanbistõn ja sugudõn julgist luōtõkst, ku Sin tāmi um ȳdõkabal jõva ja pyva, ka siz, ku mēg tämst aru äb sām, ja ku Sin tye um sieldi pyvastõm. Ānda näntõn ja mäddõn amadõn alastõmt, ku mēg entš sydamd Sin puōl kiērõm, Sin tāmiz pierrõ näḍi oigist alantõm (ja ka näḍi läpši, kis mäddõn āt iēnd, Sin sõna 
kūldzistõks kazatõm). Kaim mäddõn entš alastõmt, aga ama emiṇ muraglist kuodan usk parantõmizõks, laz ne amad entšlistõks Sinnõn palkõgõd ȳdõkabal jumalkārtamizõs ja ārmastõksõs ja jelsizõs luōtõksõs iganiz pyvastõmiz päl, Sin pyva nimmõn ouvõks ja kītõksõks löb mäd Izand Jezus Kristus, kis kuōlõmõn um võimiz võttõn ja jelamist ja äbkaddõjist volmist um sieldõmõ tuōnd ja kien nims mēg pālam:

6. Mäd Iza, kis Sa uōd touvõs ....

7. Āron pyvastõmi.

\section{Kirjandus}

Blumberga, Renāte 2006. Somu mācītāja Helles Kalervo Ervies darbība lībiešu ciemos 1930. gados. - Latvijas Vēstures Institūta Žurnāls 3, 76-89.

Blumberga, Renāte 2011. Liivlaste ärkamisaeg ja hõimuliikumine. - Liivlased. Ajalugu, keel ja kultuur. Koost. ja toim. Renāte Blumberga, Tapio Mäkeläinen, Karl Pajusalu. Tallinn: Eesti Keele Sihtasutus, 155-190.

Ernštreits, Valts 2010. Liivi kirjakeele kujunemine. (= Dissertationes philologiae uralicae Universitatis Tartuensis 8.) Tartu: Tartu Ülikooli Kirjastus.

Erviö, H[elle] K[alervo] 1931a. Liivin matkalta. - Hengellinen Kuukauslehti 2, 30-31.

Erviö, H[elle] K[alervo] 1931b. Liivistä ja Eestin Inkeristä. - Hengellinen Kuukauslehti 9, 160-161.

Erviö, H[elle] K[alervo] 1932. Toiminnasta Liiviläisten keskuudessa. - Hengellinen Kuukauslehti 5, 82-83.

Erviö, H[elle] K[alervo] 1933. Liiviläisten keskuudessa v. 1932. - Hengellinen Kuukauslehti 5, 108-109.

Erviö, H[elle] K[alervo] 1934. Liiviläisten keskuudessa v. 1933. - Hengellinen Kuukauslehti 5, 108-110.

Kettunen, Lauri 1948. Tieteen matkamiehen uusia elämyksiä. Murrosvuodet 1918-1924. Porvoo-Helsinki: WSOY.

Kettunen, Lauri 1960. Matkapakinoita ja muita muistelmia 1925-1960. Helsinki. LVL = Līvlist vaimli loulrāntõz, 1939. Helsinki.

Pesonen, Matti = P. M. 1930. Kuulumisia. - Hengellinen Kuukauslehti 7, $130-131$.

Pesonen, N[iilo] 1999. Hengellistä vai kansallista herätystyötä? Herättäjäyhdistyksen heimolähetystyö Viron inkeriläisten ja liiviläisten hyväksi 1930-1942. - Suomen Kirkkohistoriallisen seuran vuosikirja 87-88, 319-364.

$\overline{\mathbf{U} T}=\overline{\mathrm{Uz}}$ Testament, 1942. Helsinki. 


\section{Arhiiviallikad}

EKLA = F 175, m 19:5. K. Stalte autobiograafia. Eesti Kultuurilooline Arhiiv. Erviö, KA = H. K. Erviön arkisto. Biographica-kokoelma II. Suomen Kansallisarkisto.

Erviö, RB = Riitta Erviö väljakirjutis isa H. K. Erviö kirjadest oma naisele Hilkka Erviöle. Käsikirja koopia. Renāte Blumberga erakogu.

Jahnsson, KA = Yrjö ja Hilma Jahnssonin arkisto. Suomen Kansallisarkisto.

Pesonen, KA = Matti Pesosen perhearkisto. Suomen Kansallisarkisto.

Renāte Blumberga

Liivi instituut

Läti Ülikool

Kronvalda bulv. 4-220

LV-1010 Riia

renate.blumberga@lu.lv 


\title{
Kōrli Stalte's Livonian translations of religious texts for confirmations and funerals ${ }^{10}$
}

\author{
RENĀTE BLUMBERGA
}

This article publishes two handwritten Livonian manuscripts for the first time, found by the author of this article among the documents of Finnish Lutheran pastor Rev. Helle Kalervo Erviö (1906-1951) at the National Archives of Finland. In the 1930s, Erviö was appointed by the Awakening Society (Herättäjä-Yhdistys) to travel several times per year to the Courland Livonian villages and fulfil his pastoral duties in Livonian. The publication of these manuscripts has two goals. The first of these is to expand the existing Livonian language corpus and add to the collection of Livonian religious texts and terminology. The other is to make these texts available to researchers. These manuscripts are published in their original written form, i.e., they are not updated to the modern Livonian orthography.

Both manuscripts are translations from church handbooks. The first is a text used for confirmations and is written in Rev. H. K. Erviö's handwriting, while the second text is intended for funerals and is in the handwriting of Livonian culture worker and community activist Kōrli Stalte (1870-1947). As the manuscripts are undated and their author is not specified, this article gives information concerning their dating and provides evidence that both manuscripts were likely translated into Livonian by K. Stalte. This assessment was made based on Rev. Erviö's letters and published announcements about his work on the Livonian Coast as well as linguist Lauri Kettunen's memories and the earlier studies of the author of this article. The translation of the confirmation text into Livonian dates to the period between summer 1931 and 23 July 1932, which was the date of the first confirmation in Livonian. The funeral text, on the other hand, was translated during the period between summer 1931 and the end of 1933 .

Keywords: Livonian language, language documentation, terminology, language history, church history, Finnic languages, Lutheran

${ }^{10}$ This study was supported by the Latvian Ministry of Education and Science research programme "Latvian Language" (VPP-IZM-2018/2-0002). 